\title{
黄河流域气候与农业种植面积变化对径流的影响"
}

\author{
李华贞 ${ }^{1}$, 张 强 ${ }^{2,3}{ }^{* *}$, 顾西辉 ${ }^{4}$, 史培军 ${ }^{2,3}$ \\ (1: 中山大学水资源与环境系,广州 510275) \\ (2: 北京师范大学地表过程与资源生态国家重点实验室, 北京 100875) \\ (3: 北京师范大学减灾与应急管理研究院, 北京 100875) \\ (4: 中国地质大学环境学院,武汉 430074)
}

摘 要: 根据黄河流域 1960- 2005 年 5 个水文站逐日流量、77 个气象站 1959-2013 年逐日降水数据, 结合流域内主要 农作物种植面积及大型水库资料, 全面探讨气候与农业面积变化及人类活动对黄河流域径流变化的影响. 研究表明: 黄 河流域所有流量分位数总体呈下降趋势, 并于 1980s 中后期到 1990s 中期发生突变. 降水变化是黄河流域径流变化的主 要影响因素. 在考虑不同流量分位数情况下, 农作物种植面积变化对不同分位数径流变化的影响也有差异性. 花园口站 农作物种植面积变化对径流量量级和可变性均有显著影响; 其余 4 站各项气候变化与农作物种植指标参数较大, 虽均未 达到 $10 \%$ 的显著性水平,但仍会对径流的量级变化产生影响. 对唐乃亥站,农作物耕作面积的下降减少了灌溉用水,在 0 . 5 流量分位数时有高达 $60 \%$ 增加径流量的间接作用. 对于头道拐站, 农作物耕作面积的增加使得流域总蒸发量增加, 灌溉 用水增加, 在 0.3 流量分位数时有高达 $40 \%$ 减少径流量的间接作用. 该研究为气候变化与人类活动影响下黄河流域水资 源优化配置提供重要理论依据.

关键词: 水文过程; 趋势性;水文变异;农业种植面积;GAMLSS 模型;黄河流域

\section{Quantification impacts of climatic and agricultural changes on streamflow variations in the Yellow River Basin}

\author{
LI Huazhen ${ }^{1}$, ZHANG Qiang ${ }^{2,3 * *}$, GU Xihui ${ }^{4} \&$ SHI Peijun ${ }^{2,3}$ \\ (1: Department of Water Resources and Environment, Sun Yat-sen University, Guangzhou 510275, P.R. China) \\ (2: State Key Laboratory of Earth Surface Processes and Resource Ecology, Beijing Normal University, Beijing 100875, P.R. \\ China) \\ (3: Academy of Disaster Reduction and Emergency Management, Beijing Normal University, Beijing 100875, P.R.China) \\ (4: School of Environmental Studies, China University of Geosciences, Wuhan 430074, P.R. China)
}

Abstract: Based on daily streamflow data covering a 1960-2005 period, daily precipitation data during 1959-2013 period, together with data concerning crop areas and water reservoirs, thorough investigation is done on impacts of human activities (crop areas and water reservoirs in this study) and climatic changes (precipitation changes in this study) on hydrological processes of the Yellow River Basin. Differentiation is done on fractional contribution of climatic changes and human activities to changes in streamflow. The results indicate that percentiles of streamflow components of the Yellow River Basin are all in descending tendency and abrupt changes can be observed during mid and late 1980s and mid-1990s. The results of this study support the statement that precipitation plays the critical role in changes of streamflow across the Yellow River Basin. However, agricultural irrigation reflected by changes in crop areas can have different impacts on different streamflow components defined by different percentiles. Specifically, crop area changes have evident influences on streamflow magnitude and also variability of streamflow changes at the Huayuankou Station in the lower Yellow River Basin. Changes of climatic and crop indices are subject to minor variations but have apparent

* 国家杰出青年科学基金项目 (51425903)、安徽省自然科学基金项目 (1408085MKL23)、安徽省教育厅高校自然科 学基金项目 (KJ2016A851) 和广东省城市化与地理环境空间模拟重点实验室开放基金项目联合资助. 2017-08-16 收稿; 2017-10-28 收修改稿. 李华贞 (1993 ), 女,硕士研究生; E-mail:lihzh28@ mail2.sysu.edu.cn.

** 通信作者; E-mail: zhangq68@ bnu.edu.cn. 
effects on magnitude of streamflow. For quantiles around the median, there is up to a $60 \%$ increment in the relation between streamflow and crop areas at the Tang Naihai Station. For the lower quantiles, there is up to a $40 \%$ reduction in the relation between streamflow and crop areas at the Toudaoguai Station. The results of this study are significant scientifically and practically in management of water resources and agricultural irrigation and also matter for enhancement of human knowledge concerning hydrological processes of the Yellow River Basin under the influences of human activities and climatic changes.

Keywords: Hydrological processes; trends; hydrological alterations; crop areas; GAMLSS model; the Yellow River Basin

河川径流变化规律及成因历来是水文学研究的热点和难点, 加之黄河流域的特殊性和重要性, 越来越 多的专家学者开始关注黄河流域径流变化规律的研究. 近年来, 由于大量水文气象极端事件(如洪水和干旱 等) 的发生, 更使黄河流域径流变化研究倍受关注. 对于黄河地表水文过程的研究已有较多, 李彦涁等 ${ }^{[1]}$ 采 用不同类型小波变换对黄河流域的径流变化过程进行了分析, 指出黄河径流在不同的时间尺度所对应的径 流丰枯变化是不同的.马雪宁等 ${ }^{[2-3]}$ 认为黄河流域的河川径流主要由大气降水补给, 降水的时空不均匀性对 黄河流域天然径流量的影响十分显著. 黄荣辉等 ${ }^{[4]}$ 通过研究发现, 黄河上游和源区从 $1990 \mathrm{~s}$ 初到新世纪初 降水的减少可能是导致径流锐减的主要原因, 而同时期黄河源区气温的明显上升并没有导致此区域蒸发量 的太大变化, 它对径流变化影响不大. 这与胡彩虹等 ${ }^{[5-6]}$ 的研究结论一致, 即黄河中上游径流对降水变化敏 感, 对温度变化响应弱. Miao 等 ${ }^{[7]}$ 采用水文法研究发现气候变化主要对黄河上游水沙变化产生较大影响, 而 人类活动对中下游水沙变化产生较大影响. $\mathrm{Li}$ 等 $^{[8]}$ 利用弹性系数法分析了黄河河龙区间 1957-2010 年降 水和径流变化,发现降水对减少径流量的贡献率为 $26.4 \%$.

黄河流域农业对中国农业的发展具有举足轻重的作用, 而农业是用水最多的产业, 对流域径流过程产 生显著影响. 土地利用的改变常常会影响局地气候, 如地表反射率的改变、大面积的水库与引水灌溉会改变 地区的水分与热量条件 ${ }^{[9]}$. 李丽娟等 ${ }^{[10-12]}$ 通过研究流域径流量变化的驱动因素, 发现人类活动特别是水土 保持措施的实施, 是导致流域径流产生显著变化的主要驱动因素. 孙红雨等 ${ }^{[13]}$ 则通过 NOAA 时间序列数据 的分析, 对中国植被覆被的变化及其与气候因子的关系进行了研究. 国外在土地利用水文效应方面已有大 量研究 ${ }^{[14-16]}$. Siriwardena 等 ${ }^{[17]}$ 采用 SIMHYD 模型, 以澳大利亚昆士兰城市的 Comet 河流域为例, 分析了不同 土地利用方式对流域径流的影响. Klöcking 等 ${ }^{[18]}$ 研究了欧洲大尺度流域土地利用变化对径流的影响, 研究 认为:土地利用变化主要影响可用水量, 对极端洪水事件的影响较小. Lorup 等 ${ }^{[19]}$ 就津巴布韦 (Zimbabwe) 流 域土地利用对流域径流的影响研究表明, 由于人口的增长和农业活动强度的增加, 使得津巴布韦 6 个流域 中多数流域的年径流量均有所减少. 而国内也展开了对黄河流域土地利用水文效应方面的研究. 李广等 ${ }^{[20]}$ 研究黄土高原地区水土流失对不同土地利用/覆被方式的响应, 结果表明: 平均雨强下, 林地、休耕地、栽培 草地和天然草地的地表产流量依次降低. 侯钦否 ${ }^{[21]}$ 认为, 林地面积的增加有减弱径流的作用, 而耕地面积 的增加有增加径流的作用. 郭军庭等 ${ }^{[22]}$ 采用情景法定量分析了潮河流域土地利用和气候变化对流域径流 变化的影响. 邱国玉等 ${ }^{[23]}$ 通过 TM 遥感影像的解译,运用 SWAT 模型模拟气候干旱化和土地利用变化对泾 河流域径流的影响. 田霞飞等 ${ }^{[24]}$ 在黄河宁蒙段以 Landsat TM 和 $\mathrm{ETM}^{+}$遥感影像为基础数据源分析得出植被 覆盖度的增加使得流域径流量和输沙量均降低; 这与苏晓慧等 ${ }^{[25]}$ 在黄河上游宁蒙段水-沙变化特征分析中 的研究结果一致:近 60 年来黄河上游宁蒙段年径流量和年输沙量均呈明显减少趋势. 孙宁等 ${ }^{[26]}$ 在潮河上游 土地利用/覆被变化对年径流影响模拟中得出, 流域年径流量的减少主要源于林地的大面积增加. 陈利群 等 ${ }^{[27]}$ 采用 SWAT 和 VIC 分布式水文模型分析了 1960-2000 年黄河源区土地覆被对径流的影响, 表明土地 覆被变化对径流影响大致为 6\% 16\%. 本文针对黄河流域径流变化开展系统研究, 并从农业生产及气候变 化两个方面,对黄河流域径流变化成因做了详尽探讨.

综上所述, 影响黄河流域径流变化的因素有很多, 而已有研究多是考虑了降水与水库调节对黄河流域 地表径流过程的影响. 本文全面分析气候变化和农业种植面积变化 (土地利用) 等人类活动对径流变化的贡 献, 其中以农业种植面积变化对径流的影响为主要研究内容和创新点, 同时将年径流量细分为 21 个不同流 量分位数, 对每一个流量分位数的变化规律及成因进行了深人研究, 以期为黄河流域水资源规划、水力发电 调度和减灾防灾等提供科学依据. 


\section{1 研究区和数据}

黄河流域地处我国半干旱半湿润地区, 流域面积 75.2 万 $\mathrm{km}^{2}$, 全长 $5464 \mathrm{~km}$ (图 1), 受大气环流和季风 环流的影响, 降水集中但时空分布不均匀性十分显著, 气候干旱, 水资源圆乏. 黄河作为我国西北和华北地 区重要的供水水源, 以其占全国河川径流的有限水资源, 承担着本流域和下游数千万亩引黄灌区 (占全国国 土面积 9\%的土地) 的灌溉用水任务, 但近年来, 黄河灌溉水水质劣化和农业水资源供需矛盾等问题日益 突出 ${ }^{[28]}$.

本文选取黄河流域 77 个气象站 1960-2013 年共 54 年的逐日降水资料, 数据来源于中国气象局气候中 心; 农作物种植面积 (主要为小麦、玉米和大豆) 资料 (1950-2013 年), 数据来源于国家统计局的国家农业 数据; 黄河干流 5 个水文站 (唐乃亥、兰州、头道拐、龙门和花园口) 的逐日流量资料 (约 1959-2005 年) 和黄 河流域 24 个大型水库的年库容资料 (1950-2013 年), 数据来源于黄委水文局. 国家统计局的种植面积数据 是以行政区域为单元进行统计的. 黄河流域与行政区域并不一致, 存在一定的尺度问题, 本文是以黄河流域 在每个行政区域内所占的面积比例为权重, 并根据各个行政区域内的农业种植面积数据, 整合计算出的黄 河流域的农业种植面积数据. 具体站点位置见图 1. 数据均经系统整编, 质量可靠.

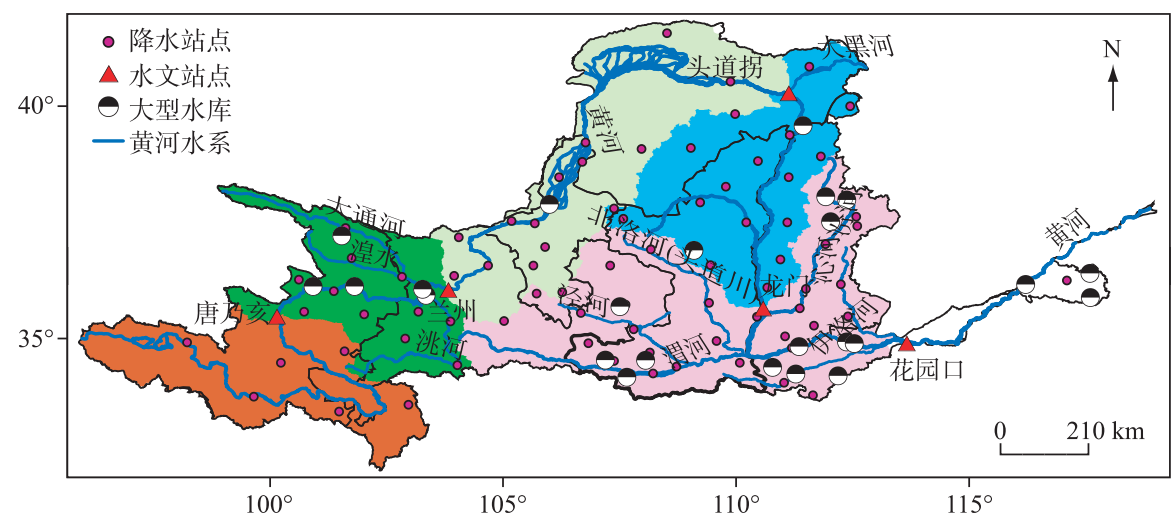

图 1 黄河流域水文站点集水区域示意图 (水文站集水区域是指该水文站以上所有流域范围)

Fig. 1 Catchment of the hydrological stations in the Yellow River Basin

\section{2 研究方法}

\section{1 指标标准化}

由于本文所采用的 3 个指标因子 (农作物指标、降水指标和水库指标) 之间存在着较大的尺度差异, 所 以需要先对 3 个指标因子做标准化处理, 以方便后续研究需要,具体处理方法参照以下公式:

$$
x=\left(x_{i}-\bar{x}\right) / \sigma
$$

式中, $x$ 为标准化后的农作物指标、降水指标或水库指标序列; $x_{i}$ 为 3 个指标因子的测量值; $\bar{x}$ 为 3 个指标因 子的均值; $\sigma$ 为 3 个指标因子的标准差.

\section{2 径流的时间变化趋势和变异分析}

时间趋势特征主要包含单调趋势变化和变异 ${ }^{[29]}$. 国际气象组织 (WMO) 建议使用非参数 Mann-Kendall 趋势检验法 ${ }^{[30]}$. Killik 等 ${ }^{[31]}$ 提出的单变异点检测方法 (AMOC), 可以克服序列正态分布假设的限制 ${ }^{[32]}$. 同 时限于本文采用时间序列的长度, 本文选择采用参数的 AMOC 检验法检测变异点.

\subsection{GAMLSS 模型和拟合优度检验}

GAMLSS 模型放宽了线性回归的限制, 具有较高的灵活性, 可以将多种解释变量纳人到模型中, 能够很 好地描述自变量和因变量间的非单调、非线性关系, 模型中的光滑函数为非参数回归方法,包括多种类型. 光滑函数的非参数形式使得模型在应用上更为灵活,可揭示自变量的非线性效应. 
假设 $Q_{i}$ 为预测值, 因变量 $q_{i}$ 相互独立且服从分布函数 $f_{Q_{i}}\left(q_{i} \mid \theta_{i}\right)$, 分布参数向量 $\theta_{i}(i=1 、 2 、 \cdots, p)$ (位 置、尺度和形状参数), 每个分布参数都可以表示为解释变量的函数, 如下文中公式 (4) 所示. 简单的说, 分位 数指的就是连续分布函数中的一个点, 这个点的左侧对应概率 (即左侧概率密度函数曲线下方覆盖的面积) 为 $p$. 按照下面公式的原则对流量分位数进行划分 ${ }^{[33]}$ :

$$
Q(p)=F^{-1}(p)=\inf \{q: F(q) \geqslant p\} \quad(0<p<1)
$$

式中, $F(q)$ 为上述分布函数 $f_{Q}$ 的原函数; $p$ 为对应不同流量分位数的概率; $q$ 为连续随机变量. 在本文中, 预 测值 $Q_{i}$ 为不同流量分布分位数的时间序列, 从年最小 $\left(Q_{0.00}\right)$ 到年最大 $\left(Q_{1.00}\right)$ 的日平均流量, 选用不同流量 对应的分布概率, 概率介于 $0 \sim 1$, 以步长为 0.05 , 均等的划分了 21 个分位数段 ${ }^{[34]}$ (分别为 $Q_{0.00} 、 Q_{0.05} 、 \cdots$ 、 $\left.Q_{0.50} 、 \cdots, Q_{1.00}\right)$.

具体到某个特定的分位数 $Q_{i}$, 我们采用有伽玛分布的广义可加模型 ${ }^{[35]}$ :

$$
f_{Q_{i}}\left(q_{i} \mid \mu_{i}, \sigma_{i}\right)=\frac{1}{\left(\sigma_{i}^{2} \cdot \mu_{i}\right)^{1 / \sigma_{i}^{2}}} \frac{q_{i}^{\left(1 / \sigma_{i}^{2}\right)-1} \exp \left[-q_{i} /\left(\sigma_{i}^{2} \cdot \mu_{i}\right)\right]}{\Gamma\left(1 / \sigma_{i}^{2}\right)}
$$

式中,位置参数 $\mu_{i}$ 和尺度参数 $\sigma_{i}$ 可以成为随时间变化的预测变量 $x_{1} 、 x_{2} 、 \cdots 、 x_{n}$ 的一个通过对数连接的线性 函数.

首先根据拟合残差 Filliben 系数 (概率点距相关系数, PPCC) 以及残差分布矩对模型拟合效果做初步判 断 ${ }^{[36]}$, 然后根据 Dunn 等 $^{[37]}$ 提出的更简单直观的标准化残差图 (normalized randomized quantile residuals) 来 进一步判断模型拟合结果的优劣. 对于经过变换后标准化的残差, 应近似服从标准正态分布, 样本点应落在 一定宽度的水平带区域内. Normal Q-Q 图可以检验残差的正态性, 如果标准化的残差是服从标准正态分布 的样本点, 则这些点应该落在一条直线上 ${ }^{[38]}$.

\subsection{GAMLSS 不同指标系数的变化特征}

如前所述, 我们将考虑 3 个因素, 每年的降雨量 $\left(x_{\mathrm{r}}\right)$ 、主要农作物的耕作面积 $\left(x_{\mathrm{a}}\right)$ 和大型水库 $\left(x_{\mathrm{s}}\right)$, 作为协 变量来反映气候、农业耕作面积变化和人类活动对黄河流域径流量的影响. 国内外对于农业与降水相互作用 的研究,总体上看尚无比较成熟的方法可供借鉴 ${ }^{[35]}$, 仍处于积极探索和不断发展阶段. 本文中我们加人了一个 交互作用项, 就农业耕作面积的变化对径流量变化的影响做初步探索 ${ }^{[35]}$. 农业耕作面积本身并不影响径流量, 但其可以通过与降水相互作用,而改变流量的分布. 参数与协变量的依赖关系可以表示如下:

$$
\begin{aligned}
& \mu_{i t}=\lg \left(\alpha_{0 i}+\alpha_{1 i} \cdot x_{r t}+\alpha_{2 i} \cdot x_{r t} \cdot x_{a t}+\alpha_{3 i} \cdot x_{s t}\right) \\
& \sigma_{i t}=\lg \left(\beta_{0 i}+\beta_{1 i} \cdot x_{r t}+\beta_{2 i} \cdot x_{r t} \cdot x_{a t}+\beta_{3 i} \cdot x_{s t}\right)
\end{aligned}
$$

式中, 位置参数 $\mu_{i}$ 和尺度参数 $\sigma_{i}$ 均为正的对数连接函数, $\alpha$ 和 $\beta$ 均为各项系数. $Q_{i}$ 的期望值为 $\mu_{i}$, 方差为 $\mu_{i}^{2} \cdot \sigma_{i}^{2}$.

伽玛 (GA) 分布是统计学的一种连续概率函数, 又因其定义区间始终为正值且实际应用时具有很大的 灵活性, 能够很好地反映不同流量分位数随时间变化的情况, 所以, 本文选择采用伽玛分布为广义可加模型 的最优分布. 通过分析两参数 GA 分布对应于不同指标因素的系数 (即式 (4) 的各项系数 $\alpha_{0} \sim \alpha_{3}$ 和 $\beta_{0} \sim \beta_{3}$ 随 不同流量分位数的大小和正负变化来反映各个指标与径流的正向或负向相关关系; 由对应指标系数是否达 到 10\%显著性水平的情况,可以反映控制径流量量级和可变性的关键因素.

\section{5 农业面积变化对径流的边缘影响效应}

为更好评价农业在不同流量分位数与降雨量之间的作用关系, 首先分析降雨量的变化对不同流量分位 数期望的边缘影响效应. 我们考虑一个改变的程度,通过分析 2005 年和几个不同参考年之间农业变化下径 流差异百分比来反映农业面积变化对径流的边缘影响效应 ${ }^{[35]}$. 径流差异百分比值越大, 表明农业面积变化 对径流的边缘影响效应越强. 因各个水文站控制流域面积内的农业发展存在差异,选择的参考年应代表该 流域 5 个水文站各自农业发展的不同时期. 建立如下方程 ${ }^{[35]}$ :

$$
\frac{\left[\alpha_{1 i}+\alpha_{2 i} \cdot x_{a}(2005)+\alpha_{3 i}\right]-\left[\alpha_{1 i}+\alpha_{2 i} \cdot x_{a}(t)+\alpha_{3 i}\right]}{\alpha_{1 i}+\alpha_{2 i} \cdot x_{a}(t)+\alpha_{3 i}}
$$

式中，对唐乃亥站，t 取 1966、1986 和 1999 年; 对兰州站, $t$ 取 1967、1986 和 1996 年; 对头道拐站, $t$ 取 1960、 1986 和 1999 年; 对龙门站, $t$ 取 1965 、1986 和 1990 年;对花园口站, $t$ 取 1950、1956、1982 和 1986 年. 


\section{3 结果}

\section{1 指标标准化}

图 2 为黄河流域 5 个水文站点降水、水库库容和农作物种植面积 3 种指标年序列数据的标准化图. 对于 水库指标, 唐乃亥站集水区域内无大型水库调蓄 (图 1), 所以对其余 4 站考虑了水库库容指标的影响 (图 2 ). 因各个水库建成时间不完全一致, 而水库库容数据只有水库建成之后才会有, 所以在处理水库数据序列 时, 依照的原则是, 在还未有水库建成的时间段, 将水库库容视为零, 有水库建成时, 对照相应建成年份, 依 次累加各个建成水库的库容数据, 以保证水库数据序列与水文气象及统计数据序列年限保持一致, 最后对 形成的水库数据序列做标准化处理, 并以此序列作为输人项输人模型. 对于农作物种植面积指标, 除头道拐 站 (图 2c) 呈波动上升趋势外, 其他 4 站均呈波动下降趋势 (图 2), 其中, 在 1950-1957 年时段内均呈上升 趋势,这可能与当时我国农业生产处在恢复时期有关.
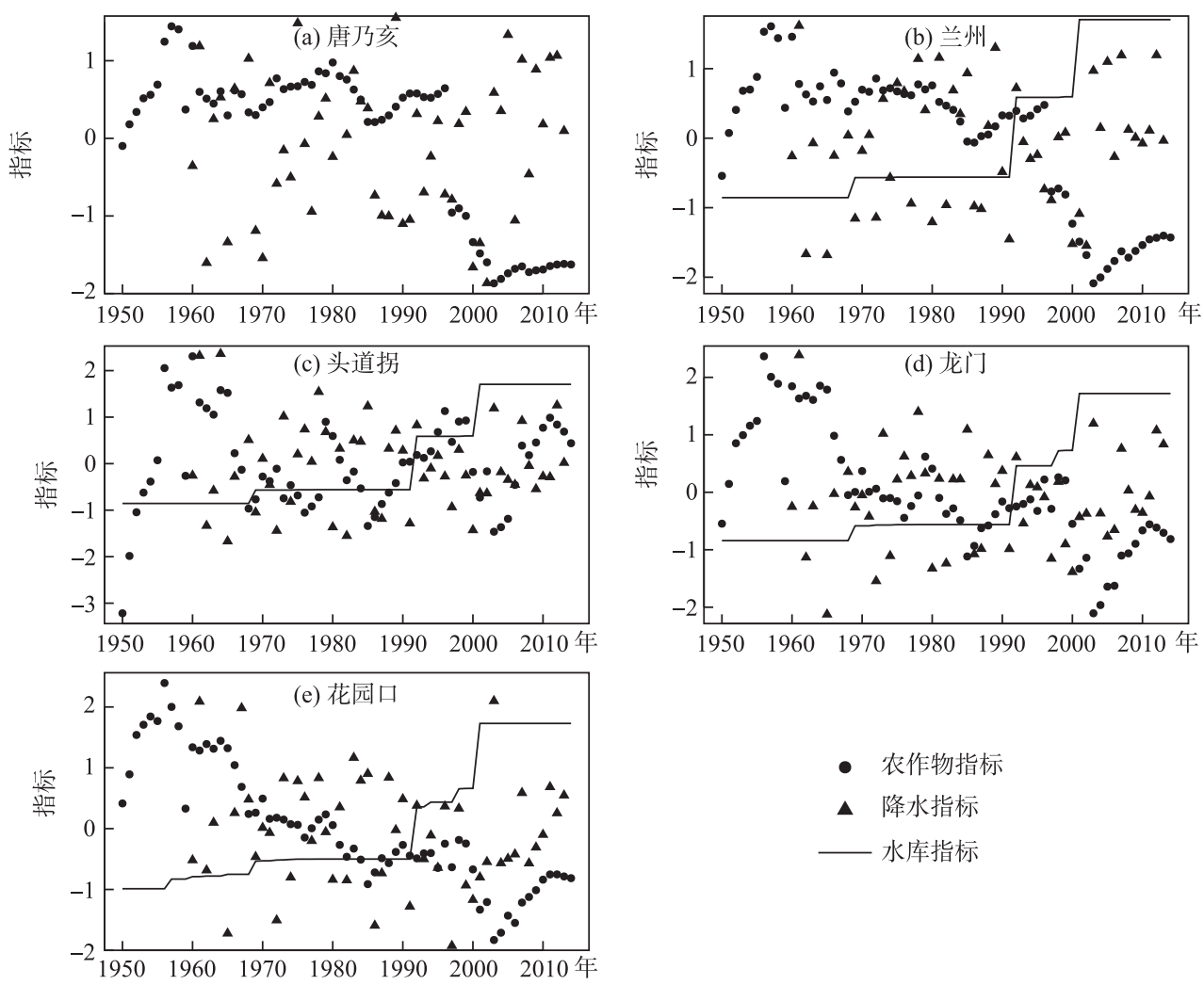

图 2 黄河流域水文站点 3 种指标标准化图

Fig.2 Temporal changes of the standardized indices at hydrological stations of Yellow River Basin

\section{2 径流的时间变异和趋势特征}

图 3 为黄河流域 5 个水文站点的径流时间变化趋势和突变点图. 其中, 图中实线代表不同流量分位数下 MK 检测统计值的大小, 统计值大于 0 , 表示时间序列呈上升趋势, 统计值小于 0 , 表示时间序列呈下降趋势, 统 计值的绝对值大于 1.96 表示趋势达到 0.05 显著性水平; 图中柱状图形代表流域 5 个站点的不同流量分位数发 生突变的时间. 黄河流域所有流量分位数总体呈下降趋势, 其中除黄河流域上游的唐乃亥站呈下降趋势外, 其 余 4 站大部分呈显著下降趋势,这是由于在水土保持生态建设和退耕还林还草政策的推动下,黄河流域农业 耕作面积总体不断下降, 而林地面积增加, 流域蓄水截流能力增强, 产流功能减弱 ${ }^{[39]}$, 造成黄河径流的大幅度 减少, 并且越向下游, 引水等人类活动加剧, 流域径流的减少幅度越大, 这可能也是引起黄河下游断流的重要 
原因之一. 流域 5 个站点的所有流量分位数均存在达到 0.05 显著性水平的突变点, 且突变多发生于 1980s 中 后期到 1990s 中期, 这与黄荣辉等 ${ }^{[4,40-41]}$ 得出的结论相一致,即黄河流域年径流量自 1985 年以来呈显著下降趋 势, 这与黄河断流现象发生和趋于严重的时间相一致. 自 2001 年底小浪底主体工程竣工以来, 其对黄河下游 防洪、防凌、工农业供水和发电等均起到重要作用,极大的改善了黄河流域径流显著下降的现象.
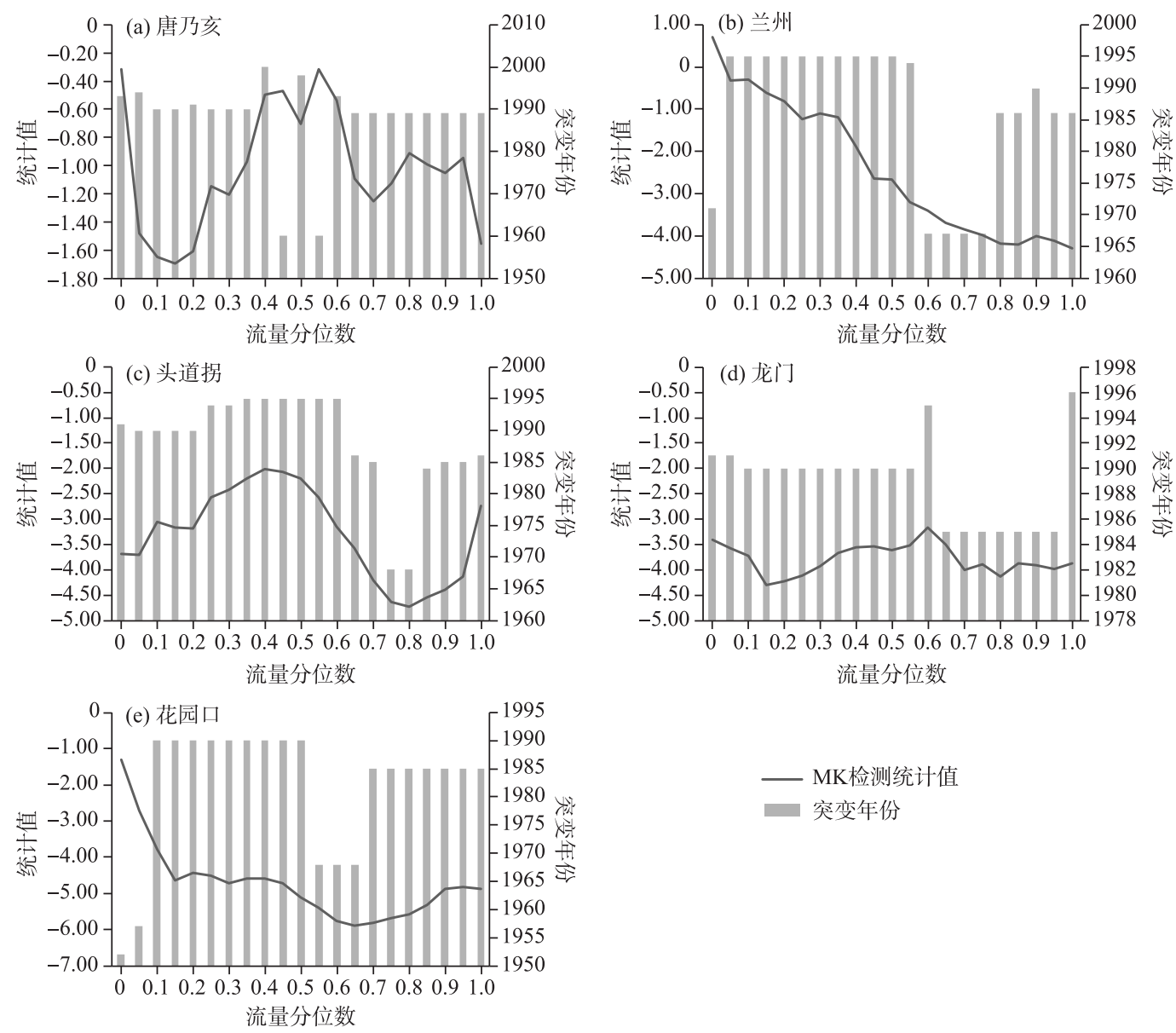

图 3 黄河流域 5 个水文站点的径流时间变化趋势和突变点

Fig. 3 Trends and change points of streamflow series at 5 hydrological stations in the Yellow River Basin

\subsection{GAMLSS 径流模拟和拟合优度检验}

因文章篇幅有限, 本文在此模块选用花园口站为代表站,将站点不同流量分位数建模的结果用图形展 示出来,其余 4 站不作展示. 图 4 显示了花园口站在考虑 3 个指标因素的条件下,不同流量分位数建模的结 果 (从低到高选取了 6 个不同的流量分位数). 无论在高值期还是低值期,这些模型都能很好地描述不同流 量分位数随时间变化的情况. 不同流量分位数随时间变化的规律大体相一致, 且均在 $1960 \mathrm{~s}$ 初期有一个非常 明显的上升波动, 这可能与黄河流域 1958 年发生的洪水事件有关(图 4). 此外,不同流量分位数下的观测值 基本在中位数线 ( $50 \%$ 分位数) 附近波动, 且均在 5\% 和 $95 \%$ 分位数的限制和约束范围内, 这也进一步说明了 花园口站模型拟合效果较好.

通过检查模型的残差来评估所有流量分位数模型的拟合质量. 花园口站所有流量分位数序列 GAMLSS 模型拟合残差 Filliben 系数 (概率点距相关系数, PPCC) 以及残差的分布矩见表 1 , 结果表明模型拟合残差 Filliben 系数基本都高于 0.95 ,表明模型残差均较好地服从正态分布,模型拟合质量较好. 花园口站拟合模型 


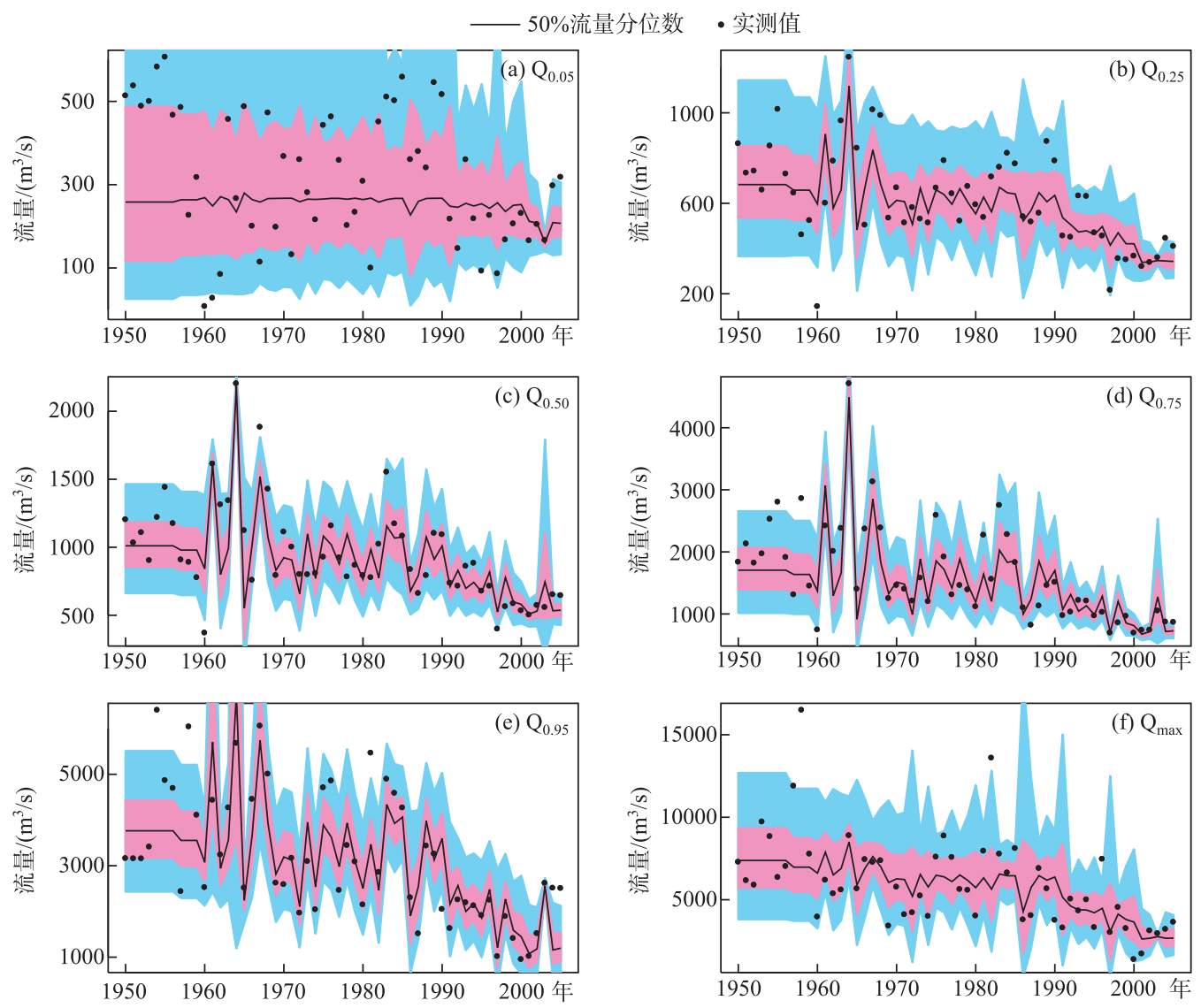

图 4 花园口站不同流量分位数建模结果

(红色区域为 $25 \%$ 和 $75 \%$ 分位数范围,蓝色区域为 $5 \%$ 和 $95 \%$ 分位数范围)

Fig.4 Statistical modeling of different discharge quantiles over time at Huayuankou Station

的标准化残差可以看出, 标准化残差的分布比较均匀, 核密度估计图接近标准正态分布, QQ 图中残差的样 本点基本落在一条直线上,进一步印证了花园口站基于 GA 分布的模型拟合效果较好(图 5).

\subsection{GAMLSS 不同指标系数的变化特征}

两参数 Gamma 分布对应于不同指标因素的系数 (即式 (4) 的各项系数 $\alpha_{0} \sim \alpha_{3}$ 和 $\beta_{0} \sim \beta_{3}$ ) 随不同流量分 位数的变化情况, 可以反映控制径流量量级和可变性的关键因素 (图 6). 其中, 图 6 中各个子图的横轴均代 表不同的流量分位数值, 纵轴则分别代表公式 (4) 中的各项系数值 $\alpha_{0} \sim \alpha_{3}$ 和 $\beta_{0} \sim \beta_{3}$, 且黑色填充的点代表参 数达到 $5 \%$ 的显著性水平; 灰色填充的点代表参数达到 $10 \%$ 的显著性水平; 白色点代表参数未达到 $10 \%$ 的显 著性水平, 而显著性水平可以反映此项指标参数对径流量量级和可变性的影响情况. 对于 5 个水文站点, 位 置参数 $\mu$ 的截距 $\alpha_{0}$ 均如预期, 随流量分位数的增加而单调增加. 另一方面, 对于尺度参数 $\sigma$ 的截距 $\beta_{0}$, 除花 园口站随流量分位数的增加而有减少的趋势外, 其余 4 站在低流量分位数时随流量分位数的增加而减少, 在高流量分位数时随流量分位数的增加而增加. 且系数 $\alpha_{0}$ 和 $\beta_{0}$ 在不同流量分位数下均达到了 $5 \%$ 的显著性 水平 (图 6). 位置参数 $\mu$ 不同指标因素的系数 $\alpha_{1} 、 \alpha_{2}$ 和 $\alpha_{3}$ 随流量分位数的变化规律各不相同. 正如前文所 述, 降水是一个非常重要且有积极正向作用的影响因子, 五站的系数 $\alpha_{1}$ 在不同流量分位数时均为正值 (图 6), 且这个由降水影响的指标参数基本都达到 $5 \%$ 的显著性水平, 表明降水变化对径流量的量级和可变性均 有显著影响, 即降水量的增加会显著增加径流, 这与胡彩虹 ${ }^{[5]}$ 和王国庆等 ${ }^{[6]}$ 得到的黄河中上游径流对降水 变化敏感, 对温度变化响应弱结论一致. 
表 1 不同流量分位数拟合残差的分布矩以及计算的 Filliben 系数值

Tab.1 Residuals moments of different discharge quantiles and computed Filliben coefficient

\begin{tabular}{cccccc}
\hline 分位数 & 均值 & 方差 & 偏斜系数 & 峰度系数 & Filliben 系数 \\
\hline 0 & 0.03 & 1.04 & -1.35 & -1.35 & 0.947 \\
0.05 & 0.03 & 1.05 & -1.42 & 6.45 & 0.946 \\
0.10 & 0 & 1.02 & -0.88 & 4.54 & 0.973 \\
0.15 & 0 & 1.01 & -0.52 & 3.18 & 0.985 \\
0.20 & 0 & 1.02 & -0.75 & 3.75 & 0.976 \\
0.25 & 0 & 1.02 & -0.76 & 3.90 & 0.975 \\
0.30 & -0.01 & 1.02 & -0.41 & 2.76 & 0.991 \\
0.35 & -0.01 & 1.02 & -0.42 & 3.04 & 0.990 \\
0.40 & 0 & 1.02 & -0.38 & 2.67 & 0.991 \\
0.45 & 0.01 & 1.02 & -0.34 & 2.45 & 0.990 \\
0.50 & 0 & 1.02 & -0.30 & 2.34 & 0.991 \\
0.55 & 0 & 1.02 & -0.37 & 2.32 & 0.987 \\
0.60 & 0.01 & 1.02 & -0.26 & 2.32 & 0.990 \\
0.65 & 0.02 & 1.03 & -0.08 & 2.36 & 0.994 \\
0.70 & 0.02 & 1.03 & -0.03 & 2.55 & 0.996 \\
0.75 & 0.02 & 1.03 & -0.17 & 2.28 & 0.992 \\
0.80 & 0.02 & 1.03 & -0.11 & 2.24 & 0.993 \\
0.85 & 0.02 & 1.03 & -0.11 & 2.13 & 0.992 \\
0.90 & 0 & 1.02 & 0.23 & 2.69 & 0.994 \\
0.95 & -0.01 & 1.02 & 0.44 & 3.12 & 0.980 \\
1.00 & -0.06 & 0.98 & 0.67 & 0.980 \\
\hline
\end{tabular}
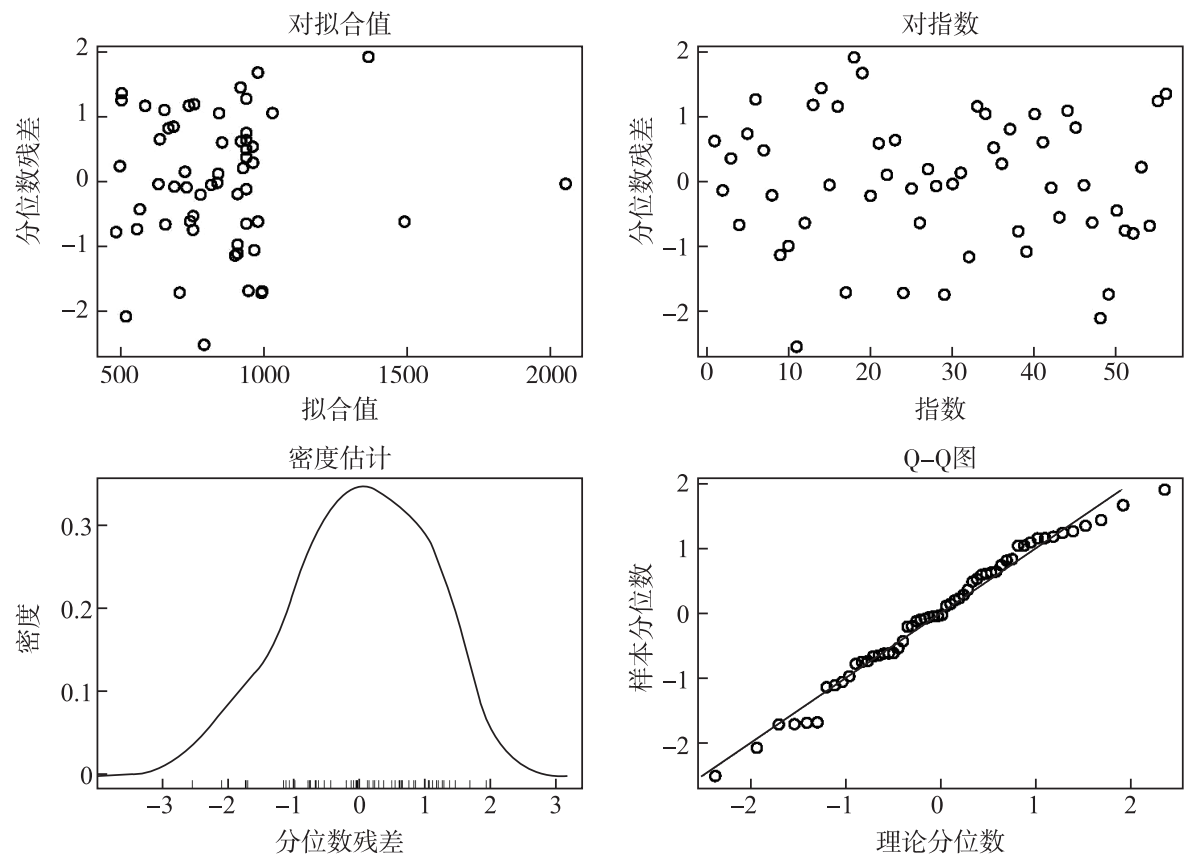

图 5 与图 4 对应的基于 $\mathrm{GA}$ 分布拟合模型的标准化残差

Fig.5 Normalized randomized quantile residuals map based on Gamma distribution fitting model with Fig.4 

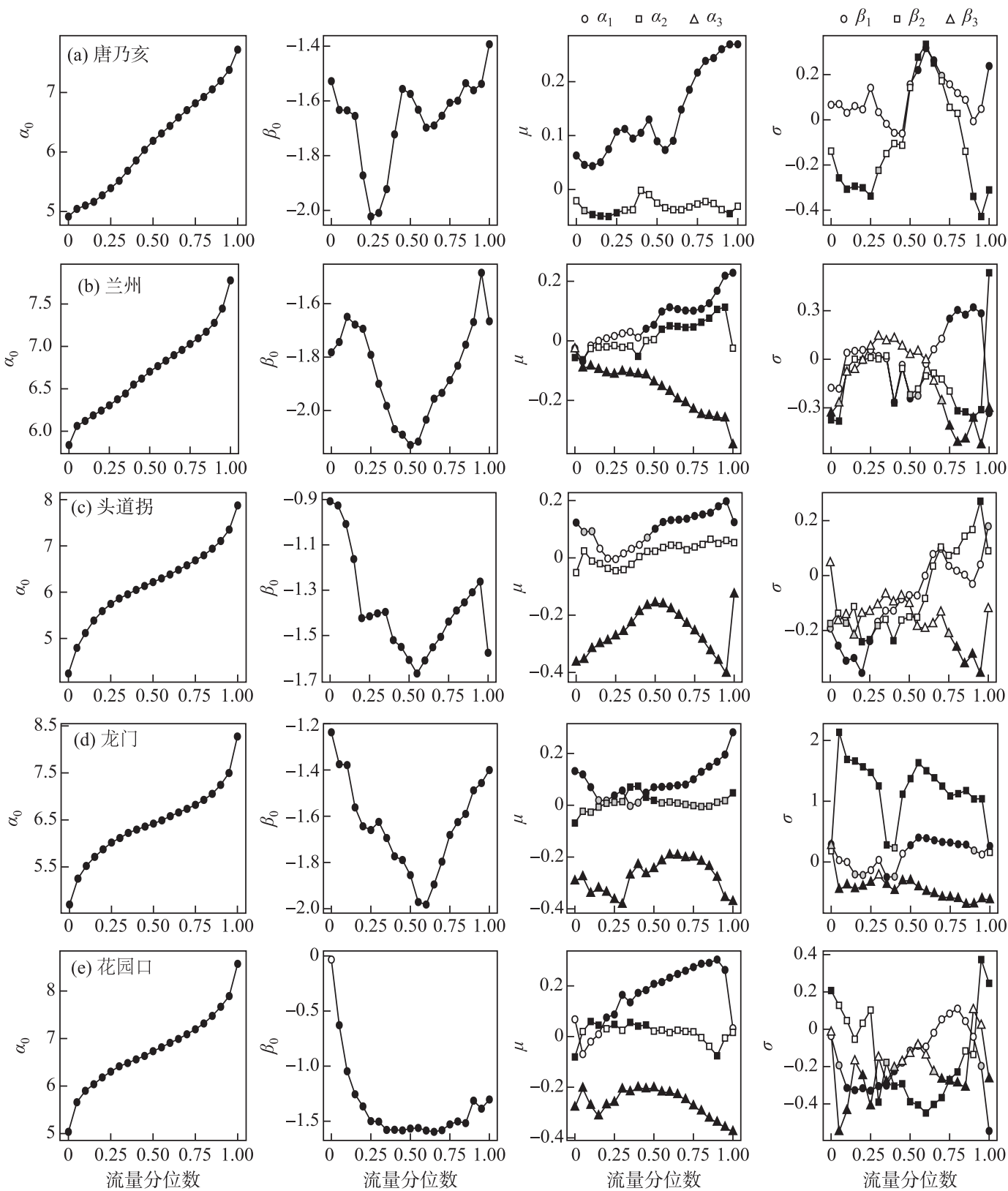

图 6 不同流量分位数下 Gamma 分布的参数依赖程度 (黑色 (灰色) 填充的点代表参数达到 $5 \%(10 \%)$ 的显著性水平;白色点代表参数未达到 $10 \%$ 的显著性水平)

Fig. 6 Dependence of the parameters of the gamma models on the different discharge quantiles

对于由主要农作物耕作面积影响的交互作用项, 不同水文站点的影响也各不相同. 其中, 对兰州、龙门 和花园口站, 系数 $\alpha_{2}$ 在高流量分位数下基本都大于 0 , 且指标参数均达到 $10 \%$ 的显著性水平 (图 $6 \mathrm{~b} 、 \mathrm{~d} 、 \mathrm{e}$ ), 表 明农作物耕作面积的下降减少了灌溉用水,有增加径流量的间接作用,这与侯钦否 ${ }^{[21]}$ 的研究结果一致. 而 对于唐乃亥站,虽系数 $\alpha_{2}$ 指标参数未达到 $10 \%$ 的显著性水平 (图 6a), 但其在不同流量分位数下均小于 0 , 表 明农作物耕作面积的下降, 有减少径流量的间接作用, 对径流量量级的影响大于对径流量可变性的影响, 这 
是由于农作物耕作面积下降而林地面积增加, 流域蓄水截流能力增强, 产流功能减弱, 同时减弱了流域的水 循环, 造成黄河径流的大幅度减少, 并且越向下游, 流域径流的减少幅度越大, 这与 Lorup 等 $^{[19]}$ 的研究结果 一致. 对于水库指标的影响, 兰州、头道拐、龙门和花园口站的系数 $\alpha_{3}$ 在不同流量分位数下均小于 0 , 且各站 的指标参数均达到 5\% 的显著性水平 (图 6b e), 表明水库对调控流域径流有非常显著的作用.

在水土保持生态建设和退耕还林还草政策的推动下, 黄河流域农业耕作面积总体不断下降, 而林地面 积增加, 流域蓄水截流能力增强, 产流功能减弱 ${ }^{[39]}$, 造成黄河径流的大幅度减少, 极大地改变了流域水文循 环状况和水资源的再分配, 这与侯饮否等 ${ }^{[21]}$ 的结论相一致, 即林地面积的增加有减弱径流的作用, 而耕地面 积的增加有增加径流的作用. 而田霞飞等 ${ }^{[24]}$ 在黄河宁蒙段以 Landsat TM 和 $\mathrm{ETM}^{+}$遥感影像为基础数据源分 析得出, 林地和耕地面积的增加均使得流域总蒸发量增加, 灌溉用水增加, 从而径流量减少, 植被覆盖度的 增加使得流域径流量和输沙量均降低. 因此耕地面积的增加会对流域径流产生两种相对的影响效果, 既可 能使产流功能增强而增加径流, 也可能使灌溉用水增加, 从而减少径流量. 两种效果叠加后, 才能得到农作 物种植面积对径流的影响作用. 这些影响径流的指标, 无论是降水、农业种植面积, 还是水库, 其对不同流量 分位数的影响差别很大,有正向作用,有反向作用,有的影响作用强,有的影响作用弱 (图 6). 5 个水文站点 研究结果的差异, 可能与水文站点集水区域经纬度高低、地形地质地貌以及农作物耕作面积在集水区域中 所占比例有关,有待进一步研究.

\section{5 农业面积变化对径流的边缘影响效应}

图 7 显示了基于方程式 (5) 的黄河流域 2005 年和 $3 \sim 4$ 个不同参考年之间农业变化下径流差异百分比 的结果. 其中, 图中一种颜色的点线代表方程式 (5) 中所选取的一个参考年下的径流差异百分比值, 我们选 择的参考年分别代表该流域农业发展的不同时期, 结果表明与 2005 年越为接近的年份百分比变化趋势越 为平缓,农业种植面积变化对径流的间接影响越弱. 唐乃亥站在低流量分位数时,农业面积的下降对径流有 $20 \%$ 的减弱作用, 随着流量分位数的增加, 农业变化通过降雨对径流的间接影响逐渐增强, 从低流量分位数 时的负值变为高流量分位数时的正值, 在 0.35 流量分位数时趋近于 0 (图 7a). 兰州站在低流量分位数时,农 业面积的下降对径流有 30\% 的增强作用, 从低流量分位数时的正值变为高流量分位数时的负值, 在 0.35 流 量分位数时, 径流差异百分比接近于 0 , 随着流量分位数的增加, 农业面积的下降产生减小径流的间接影响, 特别是对于年最大洪峰流量,农业面积的下降对径流有高达 70\% 的减弱作用 (图 7b). 头道拐站在低流量分 位数时, 农业面积的上升对径流有高达 40\% 的减弱作用 (图 7c), 这与图 6c 结果一致. 另外, 相比 1960 和 1986 年, 1999-2005 年的径流差异百分比变化趋势较为平缓. 龙门站的径流差异百分比在不同流量分位数 下均小于 0 , 但总体来说有随流量分位数的增加而趋于 0 的趋势, 在 0.05 流量分位数时, 农业面积的下降对 径流有高达 70\% 的减弱作用 (图 7d), 这与图 6d 结果一致. 花园口站在低流量分位数时, 农业面积的下降对 径流有高达 $35 \%$ 的增强作用, 但随后径流差异百分比在不同流量分位数下均小于 0 , 在高流量分位数时, 农 业面积的下降对径流有高达 70\% 的减弱作用 (图 7e), 这与花园口站农作物耕作面积的变化趋势 (图 2e) 相 一致,这说明花园口站农业面积的下降对减少径流起着重要作用. 总体来说, 5 个站点 2005 年和 $3 \sim 4$ 个不 同参考年之间农业变化下径流差异百分比基本都小于 0 , 农业变化对径流整体呈减弱作用,但各个站点的百 分比随流量分位数的变化走势与其农业种植面积的变化趋势大体保持一致. 这说明黄河流域农业耕作面积 总体不断下降对减少径流起着重要作用, 它通过改变流域植被类型, 使植被蓄水截流能力增强, 产流功能减 弱 ${ }^{[39]}$, 同时减弱了流域的水循环, 造成黄河径流的大幅度减少, 并且越向下游, 加之引水等人类活动加剧, 流 域径流的减少幅度越大, 这可能也是引起黄河下游断流的重要原因之一. 而自 2001 年底小浪底主体工程竣 工以来,其对黄河下游防洪、防凌、工农业供水和发电等均起到重要作用.

\section{4 结论与讨论}

本文基于 GAMLSS 模型探讨了气候变化、农业面积变化等人类活动对黄河流域径流的影响. 首先,在模 型中加人了一个农业耕作面积与降雨的交互作用项, 就农业耕作面积变化对径流的影响进行初步探索. 其 次, 选取 21 个不同流量分位数进行了研究, 而不是集中在某一个特定的流量分位数, 更细致地反映了气候 和土地利用变化对不同流量分位数的不同影响. 

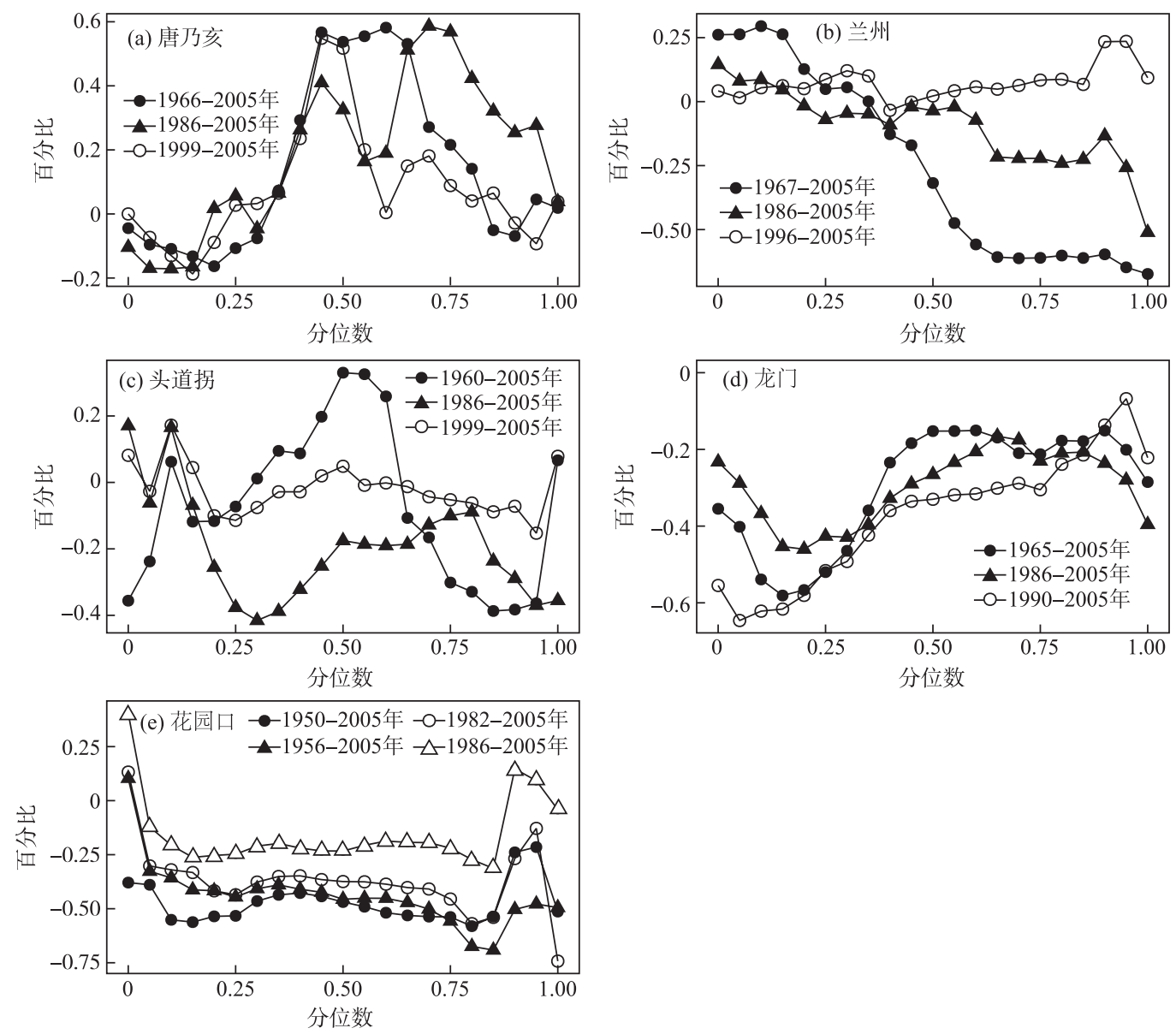

图 7 从不同参考年到 2005 年不同分位数下农作物种植面积对降水径流关系的影响变化

Fig.7 Changes in the impact of cultivated area on the relation between rainfall and average discharge for different quantile levels between the year 2005 and different reference years

1) 黄河流域所有流量分位数总体呈下降趋势, 并于 1980s 中后期到 1990s 中期发生突变, 其中除黄河流 域上游的唐乃亥站呈下降趋势外,其余 4 站大部分呈显著下降趋势, 且达到 0.05 显著性水平,这与黄荣辉 等 ${ }^{[4]}$ 、常军等 ${ }^{[40]}$ 和李春晖等 ${ }^{[41]}$ 得出的结论相一致, 即黄河流域年径流量自 1985 年以来呈显著下降趋势, 这 与黄河断流现象发生和趋于严重的时间相一致. 流域内降水和农作物种植面积的减少、大型水库对降水形 成地面径流的拦蓄以及较大的土壤蓄水和蒸散发能力是产生这种现象的主要原因. 另外, 就区域而言, 气候 变异 (主要指降水变化) 对黄河中游径流的影响大于其对上游径流的影响. 这与胡彩虹 等 $^{[5]}$ 和王国庆等 ${ }^{[6]}$ 得 到的黄河中上游径流对降水变化敏感等结论一致.

2) 通过分析伽玛分布不同指标因素的系数随不同流量分位数的变化情况发现, 兰州、龙门和花园口站 的多项指标参数均达到 $10 \%$ 的显著性水平, 对径流量量级和可变性均有显著影响, 其中降水和水库指标对 径流量量级和可变性的影响最为显著, 基本达到 5\%的显著性水平, 农业指标的影响次之. 总的来说, 降水是 一个非常重要且有积极正向作用的影响因子,水库对径流有减弱的影响作用,这与王国庆等 ${ }^{[6]}$ 和王浩等 ${ }^{[11]}$ 得出的结论相一致, 而耕地面积的增加会对流域径流产生两种相对的影响效果, 既可能使产流功能增强而 增加径流, 也可能使灌溉用水增加, 从而减少径流量. 两种效果叠加后, 才能得到农作物种植面积对径流的 影响作用, 且其对不同流量分位数的影响差别很大, 这与李辉霞等 ${ }^{[42-44]}$ 得出土地覆被是水文过程决定性影 
响因子等结论一致.

3 ) 对唐乃亥站,农作物耕作面积的下降减少了灌溉用水, 在 0.5 流量分位数时有高达 $60 \%$ 增加径流量的 间接作用,这与侯钦否等 ${ }^{[21]}$ 的研究结果一致. 对于头道拐站,农作物耕作面积的增加使得流域总蒸发量增 加, 灌溉用水增加, 在 0.3 流量分位数时有高达 $40 \%$ 减少径流量的间接作用, 且对径流量量级的影响大于对 径流量可变性的影响. 而对于龙门站,农作物耕作面积下降而林地面积增加, 流域蓄水截流能力增强, 产流 功能减弱 ${ }^{[39]}$, 造成黄河径流的大幅度减少, 且在低流量分位数时有高达 $60 \%$ 减少径流量的间接作用. 就整 个黄河区域而言, 农作物耕作面积的变化对黄河中下游径流的影响大于其对上游径流的影响. 另外, 与其他 几个参考年相比, 与 2005 年较为接近年份的径流差异百分比变化趋势较为平缓, 可能因为随着社会的不断 发展,农业生产的变化已逐渐趋于稳定,在过去 20 年中的差异较小.

本文中考虑的影响径流的指标, 无论是降水、农业种植面积, 还是水库, 其对不同流量分位数的影响差 别较大. 但由于还有很多因素未考虑进去, 研究结果还不能很好的表达各指标对径流变化的贡献率, 可以通 过改变时间和空间尺度 ${ }^{[43-44]}$, 如从季节尺度和月尺度等 ${ }^{[42]}$ 做进一步研究.

\section{5 参考文献}

[ 1 ] Li YB, You F, Xu JX et al. A wavelet analysis on Yellow River runoff variation law. Water Resources and Hydropower Engineering, 2012, 43(1): 17-20. [李彦涁, 尤风, 徐建新等. 黄河径流变化规律的小波分析. 水利水电技术, 2012, $\mathbf{4 3}(1): 17-20$.

[ 2 ] Ma XN, Zhang MJ, Ma Q et al. Nonuniform change of precipitation in Yellow River Basin during flood period. Journal of Natural Disasters, 2013, 22(4): 92-100. [马雪宁, 张明军, 马潜等. 黄河流域汛期降水非均匀性变化规律研究. 自 然灾害学报, 2013, 22(4): 92-100.]

[ 3 ] Zhang SF, Jia SF. A Research of the impacts of uneven precipitation on the natural runoff in the Yellow River. Progress in Geography, 2001, 20(4) : 355-363. [张士锋, 贾绍风. 降水不均匀性对黄河流域天然径流量的影响. 地理科学进 展, 2001, 20(4) : 355-363.]

[ 4 ] Huang RH, Zhou DG. The impact of climate change on the runoff of the Yellow River and ecosystem and frozen soil in its source area. Chinese Journal of Nature, 2012, 34(1): 1-9. [黄荣辉, 周德刚. 气候变化对黄河径流以及源区生态和 冻土环境的影响. 自然杂志, 2012, 34(1): 1-9.]

[ 5 ] Hu CH, Wang JJ, Chai XL et al. Research advances of impact of climate change on runoff of the Yellow River Basin. Meteorological and Environmental Sciences, 2013, 36(2) : 57-65. [胡彩虹, 王纪军, 柴晓玲等. 气候变化对黄河流域径流 变化及其可能影响研究进展. 气象与环境科学, 2013, 36(2) : 57-65.]

[ 6 ] Wang GQ, Wang YZ, Kang LL. Analysis on the sensitivity of runoff in Yellow River to climate change. Quarterly Journal of Applied Meteorlolgy, 2002, 13(1): 117-121. [王国庆, 王云璋, 康玲玲. 黄河上中游径流对气候变化的敏感性分 析. 应用气象学报, 2002, 13(1): 117-121.]

[ 7 ] Miao CY, Ni JR, Borthwick AGL et al. A preliminary estimate of human and natural contributions to the changes in water discharge and sediment load in the Yellow River. Global and Planetary Change, 2011, 76(3) : 196-205.

[ 8 ] Li EH, Mu XM, Zhao GJ et al. Variation of runoff and precipitation in the hekou-longmen region of the yellow river based on elasticity analysis. The Scientific World Journal, 2014. DOI: 10.1155/2014/929858.

[ 9 ] Gao P. Streamflow and sediment discharge change trend and its response to human activities in the middle reaches of the Yellow River[Dissertation]. Beijing: Graduate University of Chinese Academy of Sciences, 2010. [高鹏. 黄河中游水沙 变化及其对人类活动的响应 [学位论文]. 北京: 中国科学院研究生院, 2010.]

[ 10] Li LJ, Zheng HX. Characteristics and driving forces of annual runoff changes for rivers in North China-A case study in the Chaobaihe River. Acta Geographica Sinica, 2000, 55(3) : 309-317. [李丽娟, 郑红星. 华北典型河流年径流演变规律 及其驱动力分析一以潮白河为例. 地理学报, 2000, 55(3):309-317.]

[11] Wang H, Jia YW, Wang JH et al. Evolutionary laws of the Yellow River Basin's water resources under the impact of human activities. Journal of Natural Resources, 2005, 20(2) : 157-162. [王浩, 贾仰文, 王建华等. 人类活动影响下的黄河 流域水资源演化规律初探. 自然资源学报, 2005, 20(2): 157-162.]

[12] Zhu HF, Zhao WW, Kang MY et al. Effect of human activities on flood season runoff in water and soil conservation region. Advances in Water Science, 2008, 19(3)：400-406. [ 朱恒峰, 赵文武, 康慕谊等. 水土保持地区人类活动对汛期径 
流影响的估算. 水科学进展, 2008, 19(3) : 400-406. ]

[13] Sun HY, Li B. Analysis of the vegetation cover change and the relationship between NDVI and environmental factors by using NOAA time series data. Jouranl of Remote Sensing, 1998, 2(3) : 204-210. [孙红雨, 李兵. 中国地表植被覆被变 化及其与气候因子关系——基于 NOAA 时间序列数据分析. 遥感学报, 1998, 2(3) : 204-210.]

[14] Roo AD, Odijk M, Schmuck G et al. Assessing the effects of land use changes on floods in the meuse and oder catchment. Physics and Chemistry of the Earth (B), 2001, 26(7/8): 593-599.

[15] Zhang YK, Schilling KE. Increasing streamflow and baseflow in Mississippi River since the 1940s: effect of land use change. Journal of Hydrology, 2006, 324(1/2/3/4) : 412-422.

[16] Legesse D, Vallet-Coulomb C, Gasse F. Hydrological response of a catchment to climate and land use changes in Tropical Africa: case study South Central Ethiopia. Journal of Hydrology, 2003, 275(1/2): 67-85.

[17] Siriwardena L, Finlayson BL, McMahon TA. The impact of land use change on catchment hydrology in large catchments: The Comet River, Central Queensland, Australia. Journal of Hydrology, 2006, 326 (1) : 199-214.

[18] KlÖcking B, Haberlandt U. Impact of land use changes on water dynamics-a case study in temperate meso and macroscale river basins. Physics and Chemistry of the Earth, 2002, 27(9) : 619-629.

[19] Lorup JK, Refsgaard JC, Mazvimavi D. Assessing the effect of land use change on catchment runoff by combined use of statistical tests and hydrological modelling: Case studies from Zimbabwe. Journal of Hydrology, 1998, 205 (3/4): 147-163.

[20] Li G, Huang GB. Effects of rainfall intensity and land use on soil and water loss in loess hilly region. Transactions of the $C S A E, 2009,25$ (11): 85-90. [李广, 黄高宝. 雨强和土地利用方式对黄土丘陵区水土流失的影响. 农业工程学 报, 2009, 25(11): 85-90.]

[21] Hou QL. Impacts of climate variability and land use change on streamflow in Jinqian River Basin[Dissertation]. Xi'an: Northwest University, 2012. [侯钦否. 气候变化和 LUCC 对金钱河流域径流变化的影响 [学位论文]. 西安: 西北大 学, 2012.]

[22] Guo JT, Zhang ZQ, Wang SP. Appling SWAT model to explore the impact of changes in land use and climate on the streamflow in a Watershed of Northern China. Acta Ecologica Sinica, 2014, 34(6) : 1559-1567. [ 郭军庭, 张志强, 王盛萍 等. 应用 SWAT 模型研宎潮河流域土地利用和气候变化对径流的影响. 生态学报, 2014, 34(6) : 1559-1567.]

[23] Qiu GY, Yin J, Xiong YJ et al. Studies on the effects of climatic warming-drying trend and land use change on the runoff in the Jinghe River Basin. Journal of Natural Resources, 2008, 23(2): 211-218. [邱国玉, 尹婧, 熊育久等. 北方干早 化和土地利用变化对泾河流域径流的影响. 自然资源学报, 2008, 23(2): 211-218.]

[24] Tian XF, Xue X, Liao J et al. Land use change in the watershed of the Ningxia-Inner Mongolia reaches of the Yellow River during 1990-2010. Journal of Desert Research, 2014, 34(4): 1167-1176. [田霞飞, 薛媡, 廖杰等. 1990-2010 年黄 河宁蒙段所处流域土地利用变化. 中国沙漠, 2014, 34(4): 1167-1176.]

[25] Su XH, Zhang XH, Tian SM. Characteristics of runoff-sediment variation in Ningxia-Inner Mongolia Reaches of the Upper Yellow River. Yellow River, 2013, 35(2) : 13-15. [苏晓慧, 张晓华, 田世民. 黄河上游宁蒙河段水沙变化特征分析. 人民黄河, 2013, 35(2) : 13-15.]

[26] Sun N, Li XB, Li ZJ et al. Simulation of impacts of changes in land use and cover on annual streamflow in the upper reach of Chaohe River Basin. Journal of Beijing Forestry University, 2008, 30(2): 22-30. [孙宁, 李秀彬, 李子君等. 潮河上 游土地利用/覆被变化对年径流影响模拟. 北京林业大学学报, 2008, 30(2): 22-30.]

[27] Chen LQ, Liu CM. Influence of climate and land-cover change on runoff of the source regions of Yellow River. China Environmental Science, 2007, 27(4) : 559-565.

[28] Zhang SW, Ding J, Liao J et al. Analysis of natural annal flow time seris in the upper reach of the Yellow River based on Wavelet Transform. Journal of Sichuan University: Engineering Science Edition, 2004, 36(3): 32-37. [张少文, 丁晶, 廖杰等. 基于小波的黄河上游天然年径流变化特性分析. 四川大学学报: 工程科学版, 2004, 36(3): 32-37.]

[29] Gu XH, Zhang Q, Sun P et al. Magnitude, frequency and timing of floods in the Tarim River, Xinjiang: characteristics, causes and impacts. Acta Geographica Sinica, 2015, 70(9): 1390-1401. [顾西辉, 张强, 孙鹏等. 新疆塔河流域洪水量 级、频率及峰现时间变化特征、成因及影响. 地理学报, 2015, 70(9): 1390-1401.]

[30] Chebana F, Ouarda TBMJ, Duong TC. Testing for multivariate trends in hydrological frequency analysis. Journal of Hydrology, 2013, 486(8) : 519-530. 
[31] Killick R, Eckley IA. Changepoint: An R package for changepoint analysis. Journal of Statistical Software, 2014, 58(3) : $1-19$.

[32] Li HZ, Zhang Q, Gu XH et al. Flooding processes in the North River Basin: Magnitude, frequency, timing and influencing factors. Journal of Wuhan University: Natural Science Edition, 2016, 62(4) : 389-400. [李华贞, 张强, 顾西辉等. 北江流域洪水量级、频率和峰现时间时空特征及影响因子. 武汉大学学报: 理学版, 2016, 62(4) : 389-400.]

[33] Hyndman RJ, Fan Y. Sample quantiles in statistical packages. The American Statistician, 1996, 50(4) :631-365.

[34] Lins HF, Slack JR. Seasonal and regional characteristics of U.S. streamflow trends in the United States from 1940 to 1999. Physical Geography, 2005, 26(6) : 489-501.

[35] Schilling KE, Chan KS, Liu H et al. Quantifying the effect of land use land cover change on increasing discharge in the Upper Mississippi River. Journal of Hydrology, 2010, 387(3) : 343-345.

[36] Zhang Q, Gu XH, Singh VP et al. Evaluation of flood frequency under non-stationarity resulting from climate indices and reservoir indices in the East River basin, China. Journal of Hydrology, 2015, 527: 565-575.

[37] Dunn PK, Smyth GK. Randomised quantile residuals. Journal of Computational and Graphical Statistics, 1996, 5(3): 236-244.

[38] Sun WW, Chen WK. Application of finite mixture distribution in vehicle insurance ratemaking. Systems Engineering, 2016, 34(5) : 144-153. [孙维伟, 陈伟珂. 有限混合分布在车险费率厘定中的应用. 系统工程, 2016, 34 (5) : 144-153.]

[39] Liu J, Li S, Ouyang Z et al. Ecological and socioeconomic effects of China's policies for ecosystem services. Proceedings of the National Academy of Sciences, 2008, 105(28) : 9477-9482.

[40] Chang J, Zhao Y, Zuo X. Relationship between runoff of Huayuankou Station on Yellow River and atmospheric circulation anomalies. Yellow River, 2014, 36(12)：11-13. [常军, 赵宇, 左璇. 黄河花园口径流突变与大气环流异常关系分 析. 人民黄河, 2014, 36(12): 11-13.]

[41] Li CH, Zheng XK, Yang ZF et al. Trends of annual natural runoff in the Yellow River Basin. Journal of Beijing Normal University: Natural Science, 2009, 45(1): 80-85. [李春晖, 郑小康, 杨志峰等. 黄河天然径流量变化趋势及其影响 分析. 北京师范大学学报: 自然科学版, 2009, 45(1): 80-85.]

[42] Li HX, Liu GH, Fu BJ. Response of vegetation to climate change and human activity based on NDVI in the Three-River Headwaters region. Acta Ecologica Sinica, 2011, 31(19): 5495-5504. [李辉霞, 刘国华, 傅伯杰. 基于 NDVI 的三江 源地区植被生长对气候变化和人类活动的响应研究. 生态学报, 2011, 31(19) : 5495-5504.]

[43] Fu BJ, Xu YD, Lv YH. Scale characteristics and coupled research of landscape pattern and soil and water loss. Advances in Earth Science, 2010, 25(7):673-681. [傅伯杰, 徐延达, 吕一河. 景观格局与水土流失的尺度特征与耦合方法. 地 理科学进展, 2010, 25(7): 673-681.]

[44] Savary S, Rousseau AN, Quilbe R. Assessing the effects of historical land cover changes on runoff and low flows using remote sensing and hydrological modeling. Journal of Hydrologic Engineering, 2009, 14(6) : 575-587. 